Abstract-The Atlantic silverside (Menidia menidia) is extremely abundant in estuaries in eastern North America, is a significant component of food webs, and is the subject of many laboratory studies; however, the ecology of the larvae of this species in estuaries is poorly known. Using 4 simple collecting gears, we sampled Atlantic silverside larvae in 2 estuaries in Rhode Island that differ in anthropogenic inputs, Pettaquamscutt River estuary and Point Judith Pond, to assess the distribution and abundance of larvae of this species. These larvae occur predominantly in waters less than $1 \mathrm{~m}$ deep and are patchily distributed. Larvae collected at depths of $0.2-0.6 \mathrm{~m}$ were significantly shorter than those collected at depths of $0.6-0.8 \mathrm{~m}-\mathrm{a}$ difference in mean total length of $\sim 2$ $\mathrm{mm}$. We also compared diets and growth rates of larvae in the 2 estuaries, using gut content analysis and otolith analysis, respectively. Copepod eggs made up $76 \%$ of the diet of larval Atlantic silverside in Pettaquamscutt River, whereas copepod nauplii made up $73 \%$ of their diet in Point Judith Pond. Growth rates of the larvae did not differ between estuaries.

Manuscript submitted 19 November 2015. Manuscript accepted 28 July 2016.

Fish. Bull. 114:435-444 (2016).

Online publication date: 23 August 2016. doi: 10.7755/FB.114.4.6

The views and opinions expressed or implied in this article are those of the author (or authors) and do not necessarily reflect the position of the National Marine Fisheries Service, NOAA.

\title{
First assessment of the field ecology of larval Atlantic silverside (Menidia menidia)
}

\author{
Miranda Lopez ${ }^{1}$ \\ Gavino Puggioni² \\ David A. Bengtson (contact author)' \\ Email address for contact author: dbengtson@uri.edu \\ 1 Department of Fisheries, Animal, and Veterinary Sciences \\ University of Rhode Island \\ 113 Woodward Hall \\ 9 East Alumni Avenue \\ Kingston, Rhode Island 02881 \\ 2 Department of Computer Science and Statistics \\ University of Rhode Island \\ 246 Tyler Hall \\ 9 Greenhouse Road, Suite 2 \\ Kingston, Rhode Island 02881
}

The Atlantic silverside (Menidia menidia) is one of the most abundant estuarine species along the east coast of North America from Nova Scotia, Canada, to Florida (Middaugh et al., 1981). Although this species has no commercial fishery value, it serves as a forage species for commercially important fish, such as bluefish (Pomatomus saltatrix), striped bass (Morone saxatilis), and Atlantic mackerel (Scomber scombrus) (Fay et al., 1983). It is perhaps best known scientifically because of the important laboratory experiments of Conover and Kynard (1981), whose work demonstrated that sex was determined by environmental factors, and of Conover and Munch (2002), whose investigation showed multigenerational reductions in fish size after size-selective "fishing" in experimental tanks. Because the adults of this species are easy to spawn in captivity (Barkman and Beck, 1976; Middaugh and Lempesis, 1976), larvae have been the subject of laboratory studies for decades. However, surprisingly, the larval ecology of this species in the field is poorly known.
In Rhode Island, Atlantic silverside occupy estuaries from March through December and migrate to open water during the winter months. Adults return after winter in an emaciated condition, then feed heavily on zooplankton in March and April to become reproductively mature, which occurs between May and early July (Huber and Bengtson, 1999). Spawning throughout the species range occurs with semilunar periodicity, and eggs are deposited in discrete areas in the upper intertidal reaches of salt marshes (Middaugh, 1981; Middaugh et al., 1981; Conover and Kynard, 1984; Conover, 1985), the latter of which reduces egg predation by open-water predators (Tewksbury and Conover, 1987).

In the upper reaches of 2 estuaries in Rhode Island, the upper Pettaquamscutt River (UPR) and upper Point Judith Pond (UPJP), zooplankton communities are quite different in early spring when Atlantic silverside adults return to feed and prepare for spawning (Bengtson, 1982; Huber, 1995; Volson, 2012). The zooplankton community in the UPR is 


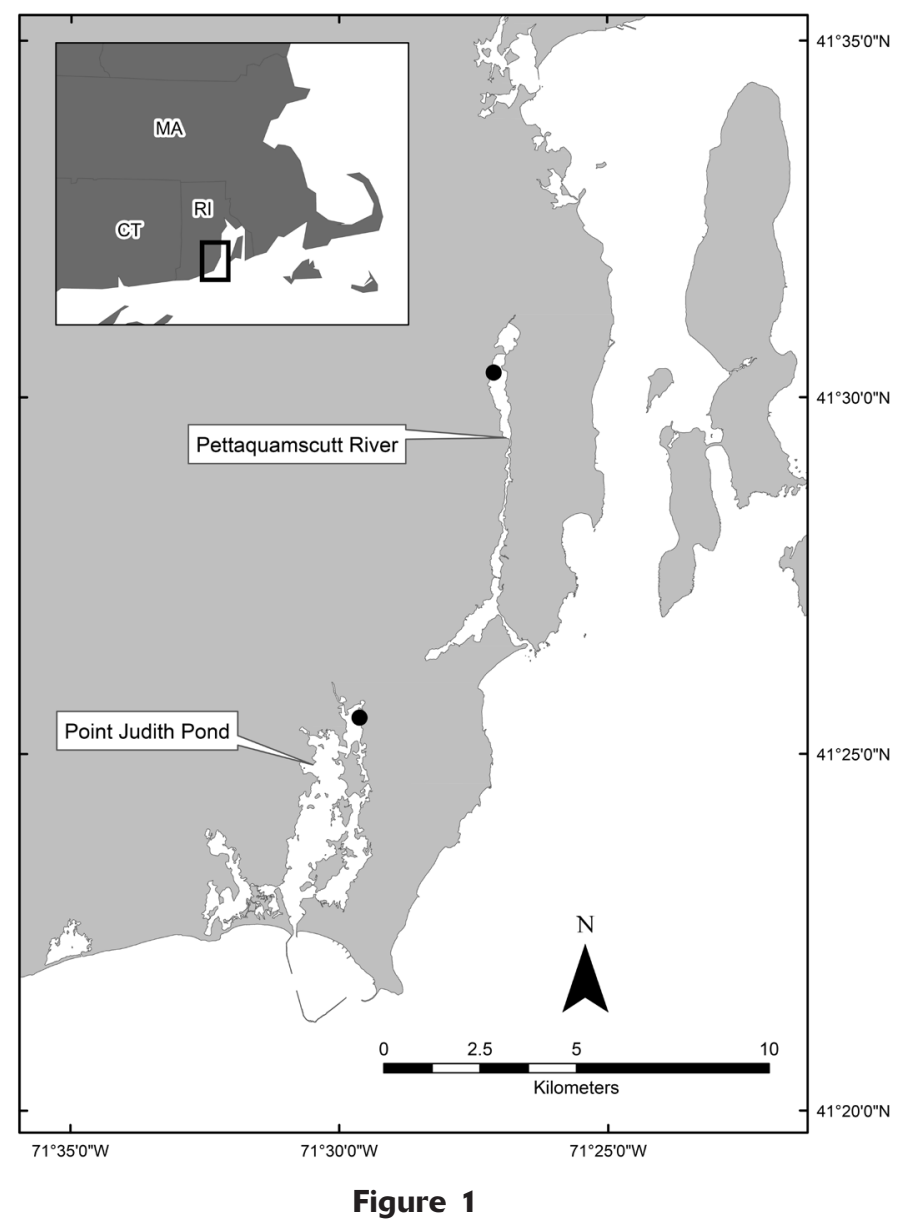

Map of the upper portions of the Pettaquamscutt River estuary and Point Judith Pond, the 2 estuaries in Rhode Island where larvae of Atlantic silverside (Menidia menid$i a$ ) were sampled in 2012 for this study. The rectangle on the smaller map indicates the location of both estuaries in southern New England. The dots on the larger map show the approximate sampling locations in each estuary.

dominated by crustaceans during early spring; their presence indicates a fairly pristine environment. The UPJP is dominated by polychaete larvae, which require a eutrophic environment. Given the general propensity of marine larval fish to feed on copepods, an a priori assumption might be made that Atlantic silverside in the UPR feed on higher quality prey than those in the UPJP. Volson (2012) examined effects of the nutritional quality of zooplankton prey from these 2 estuaries on adult Atlantic silverside and on their eggs, along with the hatching length of their larvae after incubation in the laboratory. Surprisingly, in each of 2 years, length at hatching was greater for fish from the UPJP than for fish from the UPR. It has remained unclear whether a greater length at hatching translates into different larval growth rates during the first 2 weeks of life in the field. Therefore, in this study, we examined whether it does.

Very little is known about the habitat ecology of Atlantic silverside larvae during their first 2-3 weeks of life in an estuary. Because newly hatched larvae in the laboratory are attracted to the interface between the water surface and the tank edge (D. Bengtson, personal observ.) and because adults spawn (and embryos hatch) in the upper intertidal, we suspected that larvae might be found in extremely shallow water. The feeding ecology of larval Atlantic silverside in the field is undocumented (Fay et al., 1983). Therefore, knowledge of critical elements of the field ecology of this important species during the larval period is lacking. The goals of our study, therefore, were 1) to determine the depth distribution of Atlantic silverside larvae, 2) to compare abundance and distribution of Atlantic silverside larvae between estuaries, 3) to compare feeding habits of the larvae in the 2 estuaries by analyzing gut contents, and 4) to compare growth of larvae in the 2 estuaries through age-length relationships based on otolith analysis.

\section{Materials and methods}

\section{Study sites}

Field collections took place in the UPJP and UPR (Fig. 1). These estuaries are approximately $5 \mathrm{~km}$ apart, located in Washington County, Rhode Island, and have different physical characteristics (Table 1). Point Judith Pond is a shallow coastal lagoon, 1 of 7 along the southern coast of Rhode Island, connected to Block Island Sound by a breachway $\left(\mathrm{Lee}^{1}\right)$. The Pettaquamscutt River is an annual flooded river valley that drains into Narragansett Bay (Gaines, 1975).

\section{Abundance and distribution}

To determine distribution patterns and densities (abundance per cubic meters) of Atlantic silverside larvae in the field, 4 sampling devices were used: 1) a cylindrical polycarbonate quadrat (with a diameter of $0.5 \mathrm{~m}$ to sample the land-water interface); 2) an aquarium net, $19.05 \times 26.03 \mathrm{~cm}$ with $500-\mu \mathrm{m}$ mesh, to collect larval samples in water that was $0.05-0.80 \mathrm{~m}$ deep; 3) a plankton net with a diameter of $0.2 \mathrm{~m}$, length of $0.6 \mathrm{~m}$, and 200- $\mathrm{mm}$ mesh to collect samples in water 0.15-0.91 m deep, and 4) a second plankton net with a diameter of $0.5 \mathrm{~m}$, length of $1.8 \mathrm{~m}$, and $100-\mu \mathrm{m}$ mesh to collect samples in water with depths slightly greater than $1 \mathrm{~m}$.

At both estuaries, collections occurred 7 days after the new moon of 20 May 2012 and continued for 2 weeks. A second 2-week period of sampling occurred 7 days after the full moon of 4 June 2012. These dates were chosen to collect larvae hatched during those pre-

\footnotetext{
${ }^{1}$ Lee, V. 1980. An elusive compromise: Rhode Island coastal ponds and their people. Univ. Rhode Island, Coast. Resour. Cent., Mar. Tech. Rep. 73, 65 p. [Available at website.]
} 


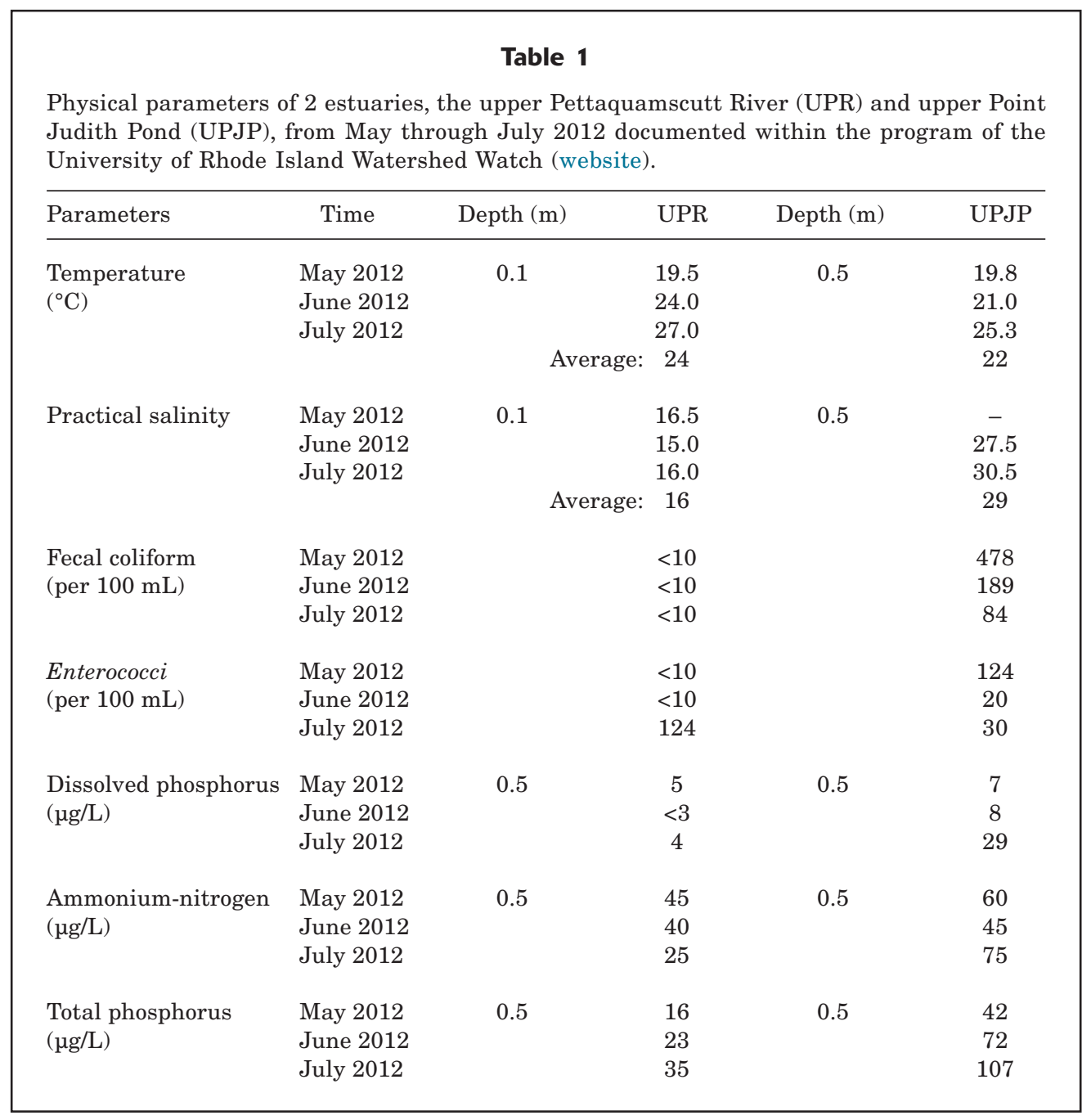

sumed semilunar spawning periods Sampling began at 0630 , an important time for determining foraging habits because this is the time when Atlantic silverside begin feeding for the day. Initially, each sampling device was used at 4 locations within each estuary to try to identify microhabitat differences. Collections on and after 14 June in the UPJP were sampled from one location only because we determined that this estuary had undifferentiated microhabitat structure. At each of the locations within the UPR and UPJP, the quadrat, aquarium net and 2 plankton nets were each used 4 times (replicates) daily. Once sampling began, it continued throughout the day until all tows and plots were complete or until weather conditions prohibited further sampling.

The quadrat was haphazardly tossed at the landwater interface. Both plankton nets were pulled along 10-m transects by means of a rope; the senior author deployed the nets in the water, walked around the transect with the rope, waited for any disturbed sediment to settle out of the water column, and quickly pulled the net over the $10-\mathrm{m}$ distance. Finally, the aquarium net was pushed along a $10-\mathrm{m}$ transect. However, on and after June 14, the aquarium net was pushed along a 1-m transect. Immediately before each sampling event, the water depth at the sampling point was measured in meters with a yard stick. In between each tow with the plankton nets and aquarium net, a 15-min waiting period allowed suspended sediment from the previous tow to settle. The quadrat on average sampled 0.010 $\mathrm{m}^{3}$ of water per sample at the land-water interface. For field collections made before 14 June, the volume of water filtered by the aquarium net was $0.496 \mathrm{~m}^{3}$ per sample. For field collections made on and after 14 June, the aquarium net filtered $0.049 \mathrm{~m}^{3}$ of water per sample because of the shorter sampling transect. The small plankton net filtered $0.324 \mathrm{~m}^{3}$ of water per sample, whereas the large plankton net filtered $1.980 \mathrm{~m}^{3}$ of water per sample. Although it was not possible to determine the sampling efficiency of each device, we assumed that the swimming speed of Atlantic silverside larvae is insufficient for them to avoid these sampling devices in any meaningful way.

Larvae that were collected for laboratory analysis 


\section{Table 2}

Catch data for each sampling device used in this study of Atlantic silverside (Menidia menidia) larvae in the upper Pettaquamscutt River (UPR) and upper Point Judith Pond (UPJP), Rhode Island, before 14 June 2012 (A), as well as on and after 14 June 2012 (B). Also included in each table are descriptions of the volume of water filtered by each sampling device. Average densities of larvae, measured in number of fish per cubic meter, are provided with standard error (SE) values in parentheses.

\begin{tabular}{|c|c|c|c|c|c|}
\hline \multirow[b]{2}{*}{ Sampling device } & \multirow{2}{*}{$\begin{array}{c}\text { Volume of water } \\
\text { sampled per tow }\left(\mathrm{m}^{3}\right)\end{array}$} & \multicolumn{2}{|c|}{$\begin{array}{c}\text { Total number } \\
\text { of larvae collected }\end{array}$} & \multicolumn{2}{|c|}{$\begin{array}{l}\text { Average density of } \\
\text { larvae }\left(\text { fish } / \mathrm{m}^{3}\right)(\mathrm{SE})\end{array}$} \\
\hline & & UPR & UPJP & UPR & UPJP \\
\hline \multicolumn{6}{|l|}{$\mathbf{A}$} \\
\hline Quadrat & 0.01 & 33 & 2 & $0.18(\mathrm{SE} 0.12)$ & $0.01(\mathrm{SE} 0.01)$ \\
\hline Aquarium net & 0.49 & 152 & 311 & $2.55(\mathrm{SE} 0.55)$ & 10.11 (SE 3.21) \\
\hline Small plankton net & 0.32 & 35 & 3 & $0.90(\mathrm{SE} 0.38)$ & $0.11(\mathrm{SE} 0.08)$ \\
\hline Large plankton net & 1.98 & 0 & 1 & 0 & 0.01 (SE 0.01) \\
\hline \multicolumn{6}{|l|}{$\mathbf{B}$} \\
\hline Quadrat & 0.01 & 8 & 1 & $0.05(\mathrm{SE} 0.03)$ & $0.02(\mathrm{SE} 0.02)$ \\
\hline Aquarium net & 0.049 & 25 & 24 & $6.00(\mathrm{SE} 3.70)$ & 20.16 (SE 9.71) \\
\hline Small plankton net & 0.32 & 2 & 0 & 0.07 (SE 0.05) & 0 \\
\hline Large plankton net & 1.98 & 0 & 0 & 0 & 0 \\
\hline
\end{tabular}

were euthanized with tricaine methanesulfonate (MS222) mixed in seawater $(90 \mathrm{~g} / \mathrm{mL})$ and preserved in either $95 \%$ ethanol (for otolith analysis) or $10 \%$ formalin (for gut content analysis). Each larva collected in the field was measured to the nearest $0.01 \mathrm{~mm}$ for total length (TL) with a dial caliper.

\section{Gut content analysis}

Foraging habits of Atlantic silverside larvae were determined by gut content analysis of preserved larvae collected from the field. In the laboratory, the gut was gently pulled apart and examined in a 50-mm Sedgewick-Rafter counting cell under a compound microscope. Each prey item was tallied and identified to the lowest possible taxon. From fish collected from the UPJP, 58 guts were examined. From fish sampled from the UPR, 51 guts were examined. All larvae dissected were between 4.18 and $9.36 \mathrm{~mm}$ TL for both estuaries. The number method was used to show food type as a percentage of the total gut contents of each larva (Hyslop, 1980). Each taxon was represented as a percentage of the total gut contents for all the larvae dissected for each estuary.

\section{Otolith analysis}

In the laboratory, one sagittal otolith was extracted from each larva, placed on a microscope slide with one drop of immersion oil (Grade A, Cargille-Sacher Laboratories $^{2}$, Cedar Grove, NJ), photographed by using a

\footnotetext{
2 Mention of trade names or commercial companies is for identification purposes only and does not imply endorsement by the National Marine Fisheries Service, NOAA.
}

light microscope camera (at $100 \times$ or $400 \times$ magnification), and its rings were counted by using the methods of Barkman (1978). Otoliths were first examined by using light microscopy (400× magnification) to count daily growth rings and in turn to determine age (in days). Measurements of the diameters of the sagittae were taken as a proxy for growth. At a later time, a second reading was completed by the same observer from the photographs taken of the sagittal otoliths. Six prehatching rings were subtracted from the total number of daily rings on each sagittal otolith because Barkman determined that the rings start to be laid down 6 days before hatching (Barkman, 1978). The sagittae did not require additional processing because the core was visible. The relation of the number of daily rings (age in days) to larval length was determined for fish from each estuary. The slopes of these linear relationships provide an estimate of growth (in millimeters per day) of larvae in each of the estuaries. All measurements were made in micrometers with the computer software program ImageJ (Abràmoff et al., 2004). We examined 17 larvae from the UPJP and 19 larvae from the UPR.

\section{Statistical analysis}

The relationship between age and length of larvae was determined for each estuary and the slopes of these regressions were analyzed with an analysis of covariance (ANCOVA). A chi-square analysis was applied to the gut content data to determine a significant difference between the feeding habits of Atlantic silverside larvae from UPJP and the feeding habits of Atlantic silverside larvae from UPR. 


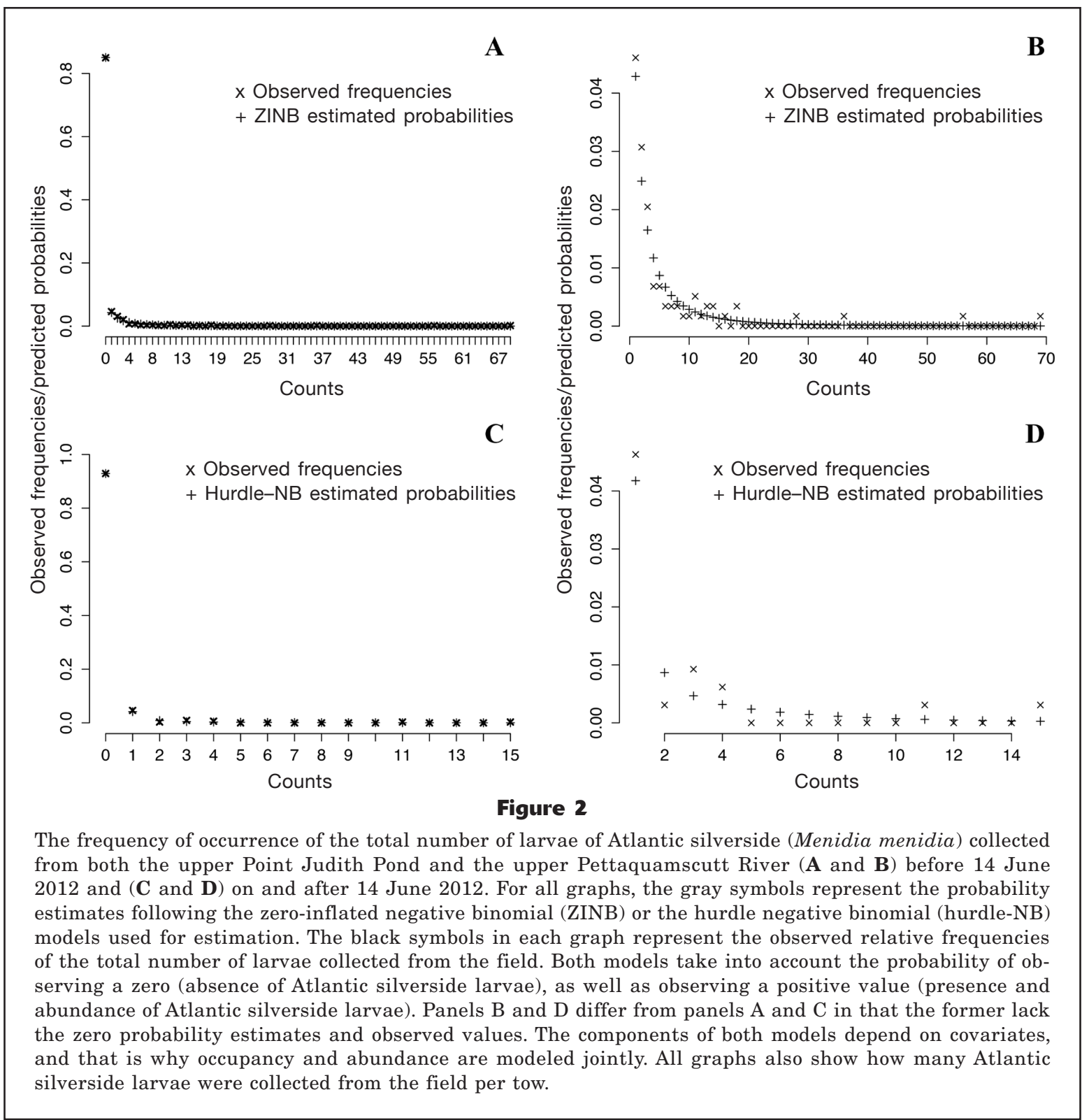

Given the large presence of zeros in the abundance data collected from the field, we worked with 2 different classes of generalized linear models that explicitly take into account this feature: zero-inflated count models and hurdle count models. A zero-Inflated model is a mixture of 2 distributions: a binary distribution for structural zeros and a distribution for the counts (typically Poisson or negative binomial) that can be zero or positive. A hurdle model is similar, except that all the zeros are modeled with the binary distribution and the distribution for the counts models only the positive values. For each class of models, we fitted 2 different distributions: the Poisson and the negative binomial (White and Bennetts, 1996). The Poisson distribution is appropriate when mean and variance of the data are similar, and the negative binomial features an addi- tional parameter to measure overdispersion (variance larger than the mean) in the data.

All these models allow specifications of covariates that can be different for the zero-inflated part and the count part. Possible covariates that could be predictors of abundance were depth of the measurements, date, site effect (UPJP versus UPR), type of collection gear or net effect (quadrat, aquarium net, small plankton net, and large plankton net). Estimation was performed by using maximum likelihood methods and implemented in the package pscl, vers. 1.4 .9 (Jackman, 2015; Zeileis et al., 2008) in the statistical software R, vers. 3.2.3 (R Core Team, 2015). Statistical significance for the parameters was assessed by using $Z$-tests. Given the relatively small amount of nonzero data, we had to choose the predictors carefully, using Akaike infor- 


\section{Table 3}

Parameter estimates from the zero-inflated negative minomial (ZINB) model for field samples of larval Atlantic silverside (Menidia menidia) collected before 14 June 2012. The top part of this table includes parameters from the ZINB model that analyzes all data values greater than zero (i.e., when a larva was collected). Site refers to the upper Pettaquamscutt River and upper Point Judith Pond in Rhode Island. Date represents the duration of sampling, 30 May 2012 through 13 June 2012. The $Z$ statistic tests whether the probability of collecting a larva is significantly influenced by site, depth, the quadrat, the aquarium net, and the small plankton net. The bottom table includes the parameters influencing the probability of having a count of zero in the data; the $Z$ statistic tests whether the probability of not collecting a larva is significantly affected by 2 of the sampling devices. SE=standard error.

\begin{tabular}{|c|c|c|c|c|c|}
\hline & Estimate & $\mathrm{SE}$ & $Z$-value & $P$-value & Significance \\
\hline \multicolumn{6}{|c|}{ Count model coefficients (negative binomial with log link) } \\
\hline Date & -0.0405 & 0.0506 & -0.802 & 0.4226 & NS \\
\hline Depth & 0.5182 & 1.2352 & 0.420 & 0.6748 & NS \\
\hline Aquarium net & 1.6155 & 0.7151 & 2.259 & 0.0239 & $* *$ \\
\hline Quadrat & -1.9364 & 1.0629 & -1.822 & 0.0684 & $*$ \\
\hline Small plankton net & -2.0110 & 1.2911 & -1.558 & 0.1193 & NS \\
\hline Site $[2$ sites] & -1.2817 & 0.4146 & -3.092 & 0.0020 & $* * *$ \\
\hline Quadrat:Site[2 sties] & 3.8550 & 1.1643 & 3.311 & 0.0009 & $* * * *$ \\
\hline Small plankton net:Site[2 sites] & 3.5268 & 0.9957 & 3.542 & 0.00040 & $* * * *$ \\
\hline Log(theta) & -1.6682 & 0.1635 & -10.206 & $<0.0001$ & $* * * *$ \\
\hline \multicolumn{6}{|c|}{ Zero-inflated model coefficients (binomial with logit link) } \\
\hline Aquarium net & -10.8903 & 381.4482 & -0.029 & 0.9772 & NS \\
\hline Quadrat & 1.4663 & 0.5074 & 2.89 & 0.0039 & $* * *$ \\
\hline Small plankton net & 1.0366 & 0.5092 & 2.036 & 0.0418 & $* *$ \\
\hline \multicolumn{6}{|l|}{$\begin{array}{l}\text { Significance codes: } \\
* * * *(P<0.001) \\
* * *(P<0.01) \\
* *(P<0.05) \\
*(P<0.1) \\
\text { NS=not significant. }\end{array}$} \\
\hline
\end{tabular}

mation criterion (AIC). We analyzed the data collected before 14 June separately from data collected on and after that date.

Finally, to determine whether the sizes of the larvae changed with depth of capture, we used analysis of variance (ANOVA) to compare the lengths of larvae collected from the following 5 depth strata: $0.0-0.2 \mathrm{~m}$; $0.2-0.4 \mathrm{~m} ; 0.4-0.6 \mathrm{~m} ; 0.6-0.8 \mathrm{~m}$; and $>0.8 \mathrm{~m}$.

\section{Results}

\section{Abundance and distribution in the field 2}

Average density and the number of larvae collected by each sampling device (Table 2) indicated that only one Atlantic silverside larva was collected with the large plankton net; therefore, this device was excluded from the remainder of the analysis. The quadrat, aquarium net, and small plankton net all collected more larvae than the large plankton net. This finding indicates that Atlantic silverside larvae are generally not found in waters greater than $1 \mathrm{~m}$ deep but can be found in wa- ters less than $1 \mathrm{~m}$ deep in the littoral zone. The quadrat, the aquarium net, and small plankton net can all be used to collect Atlantic silverside larvae from the littoral zone of estuaries.

Distribution and abundance of Atlantic silverside larvae have a discrete distribution with a high frequency of zeros on the basis of our analysis of field collections (Fig. 2), indicating that Atlantic silverside larvae have a patchy distribution in the littoral zone. In terms of maximum numbers per tow, for field collections made before 14 June, up to 69 larvae were collected per tow (Fig. 2, A and B). For field collections made on and after 14 June, up to 15 larvae were collected per tow (Fig. 2, C and D).

The results of model analysis provided the predictors that influenced the number of larvae collected, as well as the predictors that influenced the structural zeros in the data (Tables 3 and 4). For the data collected before 14 June, the use of AIC indicated that the chosen model was a zero-inflated negative binomial. The presence of larvae in the littoral zone in both estuaries correlated with date, depth, and all sampling devices, as well as with interaction terms (Table 3). Date was found to be 


\section{Table 4}

Parameter estimates for the negative binomial hurdle model obtained from field samples of larval Atlantic silverside (Menidia menidia) collected on and after 14 June 2012. The top table includes parameters from the model that analyzes all data values greater than zero (i.e., when a larva was collected). Date represents the duration of sampling, from 14 June 2012 through 25 June 2012. The $Z$ statistic tests whether the probability of collecting a larva is significantly influenced by depth and site. The bottom table includes the parameters influencing the probability of having a count of zero in the data. Site 1=Upper Point Judith Pond; site 2=Upper Pettaquamscutt River. SE=standard error.

\begin{tabular}{|c|c|c|c|c|c|}
\hline & Estimate & $\begin{array}{l}\text { andard er } \\
\text { (SE) }\end{array}$ & $Z$-value & $P$-value & Significance \\
\hline \multicolumn{6}{|c|}{ Count model coefficients (truncated negative binomial with log link) } \\
\hline Depth & 13.272 & 5.614 & 2.364 & 0.0181 & $* *$ \\
\hline Site 1 & -14.943 & 64.922 & -0.230 & 0.8180 & NS \\
\hline Site 2 & -9.885 & 64.827 & -0.152 & 0.8788 & NS \\
\hline Log(theta) & -9.077 & 64.822 & -0.140 & 0.8886 & NS \\
\hline \multicolumn{6}{|c|}{ Zero-inflated hurdle model coefficients (binomial with logit link) } \\
\hline Depth & 6.7017 & 2.0211 & 3.316 & 0.0009 & $* * * *$ \\
\hline Aquarium net & -3.4220 & 0.6359 & -5.381 & $<0.0001$ & $* * * *$ \\
\hline Quadrat & -3.9519 & 1.0082 & -3.920 & $<0.0001$ & $* * * *$ \\
\hline Small plankton net & 1.5323 & 2.2454 & 0.682 & 0.4950 & NS \\
\hline Depth : Quadrat & 1.4099 & 9.3280 & 0.151 & 0.8799 & NS \\
\hline Depth : Small plankton net & -22.8333 & 7.4331 & -3.072 & 0.0021 & $* * *$ \\
\hline \multicolumn{6}{|l|}{$\begin{array}{l}\text { Significance codes: } \\
* * * *(P<0.001) \\
* * *(P<0.01) \\
* *(P<0.05) \\
\text { NS=not significant. }\end{array}$} \\
\hline
\end{tabular}

nonsignificant (date $=-0.04, Z=-0.802, P=0.422$; Table 3 ). The number of larvae collected did not increase with depth in the littoral zone $\left(_{\text {depth }}=0.518, Z=0.420, P=0.674\right.$; Table 3 ). The different nets all had significant effects for the count part of the model. The quadrat and the small plankton net influenced the presence of zeros in the data to a larger extent than that of the aquarium net. Notice that all the estimated coefficients (Table 3) need to be interpreted, considering that the model is in the log scale (the negative binomial part) and in the logit scale (the zero-inflated part).

For field collections made on and after 14 June, given the smaller number of positive counts, we needed to implement a more parsimonious model, with fewer predictors. We tried several different specifications. For simplicity, we report that the negative binomial hurdle model offered the best performance in terms of AIC. Depth influenced the counts; depth and net type influenced the number of structural zeros. The number of larvae collected increased significantly with depth in the littoral zone (depth $=13.272, Z=2.364, P=0.0181$; Table 4).

One of the goals of our project was to determine whether the density of Atlantic silverside larvae dif- fered between the 2 estuaries. The results of the zeroinflated Poisson analysis for site indicated that, for the entire sampling period, the UPR had a higher density of Atlantic silverside larvae than the UPJP.

Results of the ANOVA of larval lengths in the depth strata from the shoreline to depths $>0.8 \mathrm{~m}$ indicated that, at the UPR, larvae captured at the depth stratum $0.2-0.4 \mathrm{~m}$ were significantly shorter (mean: 10.1 mm TL [standard deviation (SD) 3.4]) than larvae captured at the depth stratum 0.6-0.8 m (mean: $14.2 \mathrm{~mm}$ TL [SD 2.7]). At the UPJP, larvae captured at both the depth strata of $0.2-0.4 \mathrm{~m}$ and $0.4-0.6 \mathrm{~m}$ were significantly shorter (means: $7.7 \mathrm{~mm}$ TL [SD_2.5] and $7.8 \mathrm{~mm}$ TL [SD 2.2], respectively) than larvae captured at the depth stratum 0.6-0.8 m (9.5 mm TL [SD 3.1]).

\section{Gut content analysis}

Feeding habits of Atlantic silverside larvae between estuaries were significantly different $\left(\chi^{2}=622.7\right.$, $P<0.0001)$. In the UPJP, copepod nauplii made up $72.5 \%$ of total gut contents (Fig. 3). In the UPR, Atlantic silverside larvae consumed mostly copepod eggs, which made up $76.2 \%$ of the total gut contents (Fig. 3). 

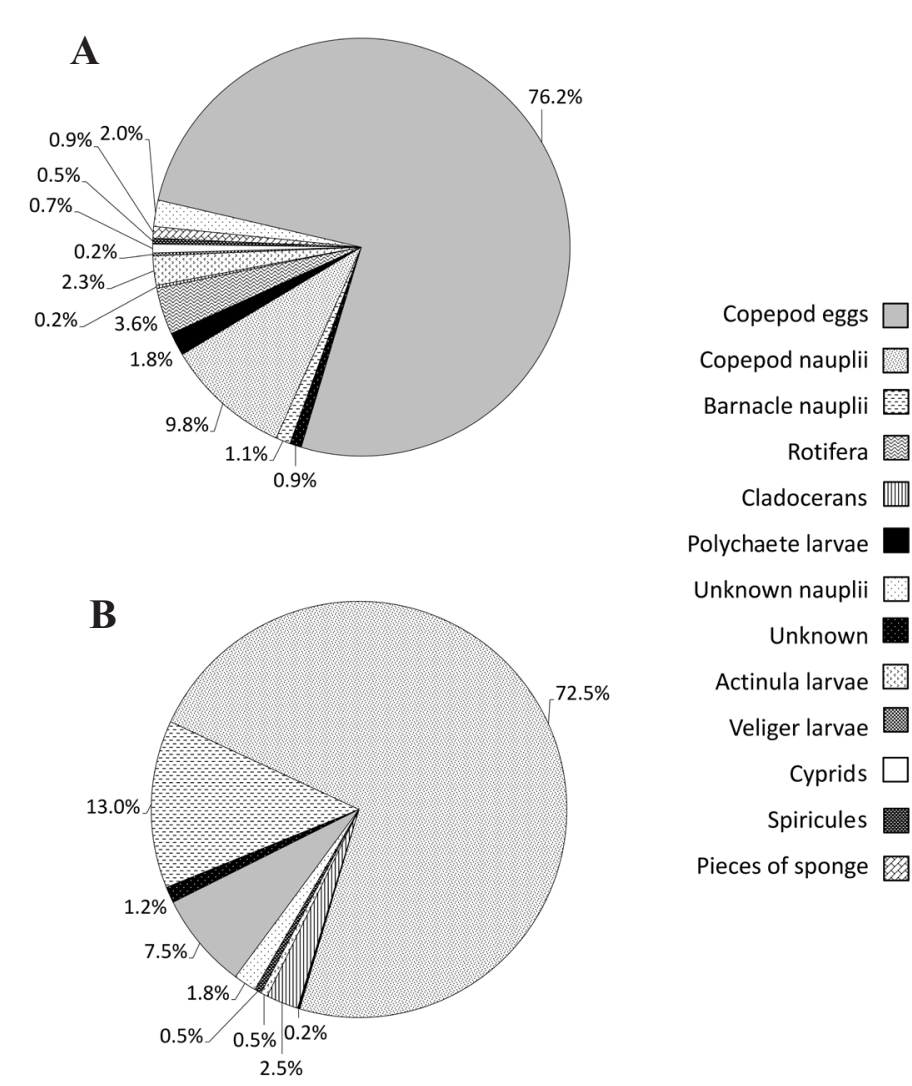

Unknown nauplii

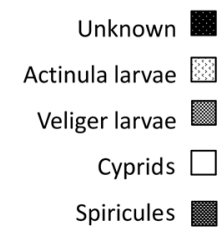

Pieces of sponge
Figure 3

Gut contents of larvae of Atlantic silverside (Menidia menidia) collected in 2012 (A) in the upper Pettaquamscutt River $(n=51)$ and $(\mathbf{B})$ in the upper Point Judith Pond $(n=58)$. Each taxon is represented as a percentage of the total gut contents for all larvae collected in each of these 2 estuaries in Rhode Island. Results from the chi-square analysis indicate a significant difference in feeding habits of Atlantic silverside larvae $(P<0.0001)$.
Field collections from the littoral zone of the UPR and UPJP during the summer of 2012 indicate that this larval fish can be captured at the shoreline interface to waters $1 \mathrm{~m}$ deep, can be collected with a variety of sampling devices, and has a patchy distribution. The 2 estuaries sampled differed in abundance of Atlantic silverside larvae and in the prey consumed by the larvae, but the larvae grew at the same rates regardless of those differences.

The quadrat, aquarium net, and small plankton net collected more larvae than the large plankton net; however, the aquarium net collected the most Atlantic silverside larvae both in absolute and per-volume-sampled terms. We acknowledge that our use of different sampling devices, chosen by necessity because of the shallow depths, and the methods we used for deploying those devices add a degree of uncertainty to our results. Nevertheless, it is clear that Atlantic silverside larvae can be collected from the shallowest water out to about a 1-m depth. Middaugh (1981), Middaugh et al. (1981), Conover and Kynard (1984), and Conover (1985) documented Atlantic silverside adults depositing eggs en masse at very discrete spawning sites in the upper intertidal zone of salt marshes. The results of our study indicate that Atlantic silverside larvae stay in the very shallow littoral zone after hatching. The distribution of Atlantic silverside larvae collected from the field in this study followed a zero-inflated Poisson model, indicating that these larvae are not distributed evenly in the littoral zone and have a patchy distribution.

The patchiness that we found in the distribution of Atlantic silverside larvae may be related to the patchiness of the egg deposition sites, although we did not specifically try to test that idea. Hewitt (1981) proposed that fish larvae have a patchy distribution because it benefits schooling. Shaw $(1960,1961)$ reported that Atlantic silverside begin to school at a size around 11-12 mm standard length. Lindsay et al. (1978) sampled ichthyoplankton in the Indian River, Delaware, in deeper waters than those that we sampled, and noted that the low abundance of atherinid larvae was not representative of their high abundance as juveniles and adults. Occupation of very shallow waters by Atlantic silverside larvae likely provides them with protection from predators. The fact that we found shorter larvae in the shallower waters and larger larvae in slightly deeper waters within the depth stratum of $<1 \mathrm{~m}$ within both estuaries indicates that these larvae are avoiding predators, or just diffusing very slowly from the hatching sites, or doing both.

Gut content data indicated that Atlantic silverside larvae in the UPR consume mostly copepod eggs, whereas larvae in the UPJP consume mostly copepod nauplii. Volson (2012) found a high abundance of cal-
This article provides the first detailed report of the field ecology of Atlantic silverside larvae, although laboratory studies on this larval species have been conducted for decades (e.g., Austin et al., 1975; Middaugh and Lempesis, 1976; Morgan and Prince, 1977; Deacutis, 1978; Bengtson, 1985; Lankford et al., 2001). 


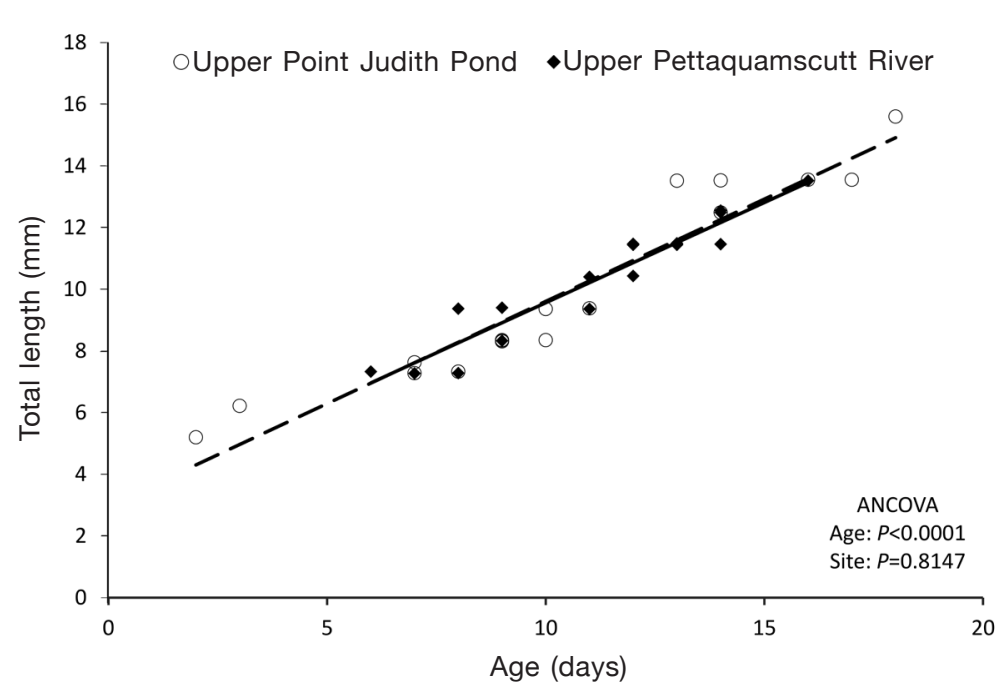

Figure 4

Growth of larvae of Atlantic silverside (Menidia menidia) collected in 2012 from the upper Point Judith Pond (UPJP) and upper Pettaquamscutt River (UPR) in Rhode Island. Linear regressions represent the age-length relationship of Atlantic silverside larvae from the UPJP (dashed line), $y=0.66 x+2.98$, and the UPR (solid line), $y=0.65 x+3.06$. In the linear equations, $y$ is total length in millimeters and $x$ is age in days. Results from the analysis of covariance (ANCOVA) indicate no significant differences in the slopes of the age-length relationship of larvae between estuaries $(P=0.8147)$. However, age is a significant indicator of the size of larvae $(P<0.0001)$.

length at hatching does not translate into faster growth for larval Atlantic silverside. Temperature influences the growth of fish. Water temperatures in the UPJP are cooler than the water temperatures in the UPR, even during the summer months (Volson, 2012) when sampling occurred for our study (Table 1). Despite a greater length at hatching for Atlantic silverside in the UPJP, the cooler water temperature in this estuary may have resulted in a slower growth rate for the larvae. As a result, larval growth was not greater in the UPJP than larval growth in the UPR.

The larval life stage is important for recruitment of adult populations. Studies on Atlantic silverside are important not only because of the abundance of this species but also because of its role as a forage fish for fisheries species and the way in which these fish influence the energetics of estuaries. We hope that the initial information presented here will stimulate researchers of estuaries to further examine the larval ecology of this important species of estuarine ecosystems.

\section{Acknowledgments}

We thank the College of the Environment

anoid copepods in the UPR and a varying zooplankton community in the UPJP, where from early spring (April through early May) through late spring (June), the dominant zooplankton present switches from polychaete larvae to copepods. Most of the sampling for our study took place in late spring, when the polychaete larvae had already settled and were not available to, or not preferred by, the larvae. The exact species of copepod from which the eggs came from, for our study, was not determined.

The significant age-length relationship for Atlantic silverside larvae in our study has been shown previously in work by Barkman (1978). Between estuaries, there was no significant difference in the age-length relationship of Atlantic silverside larvae. According to the regression coefficients in the age-length equations, the larvae in our study grew at $0.65-0.66 \mathrm{~mm} / \mathrm{d}$. Barkman et al. (1981) found that over a length range of about $12-90 \mathrm{~mm}$ TL Atlantic silverside grew at 0.84 $\mathrm{mm} / \mathrm{d}$, on the basis of an age-length relationship determined with otolith analysis, whereas Mulkana (1966) estimated a growth rate of $7-11 \mathrm{~mm} / \mathrm{month}(0.23-0.37$ $\mathrm{mm} / \mathrm{d}$ ) on the basis of length-frequency analyses of a cohort. Volson (2012) found that larval length at hatching was significantly greater for Atlantic silverside larvae in the UPJP than for larvae in the UPR.

The results from our study indicate that a greater and Life Sciences at the University of Rhode Island for a diversity teaching assistantship to M. Lopez. We also thank M. Rice for use of a microscope and image analysis software.

\section{Literature cited}

Abràmoff, M. D., P. J. Magalhães, and S. J. Ram. 2004. Image processing with ImageJ. Biophotonics Int. 11:36-42.

Austin, H. M., A. D. Sosnow, and C. R. Hickey Jr. 1975. The effects of temperature on the development and survival of the eggs and larvae of the Atlantic silverside, Menidia menidia. Trans. Am. Fish. Soc. 104:762-765. Article

Barkman, R. C.

1978. The use of otolith growth rings to age young Atlantic silversides, Menidia menidia. Trans. Am. Fish. Soc. 107:790-792. Article

Barkman, R. C., and A. D. Beck.

1976. Incubating eggs of the Atlantic silverside on nylon screen. Prog. Fish-Cult. 38:148-150. Article

Barkman, R. C., D. A. Bengtson, and A. D. Beck.

1981. Daily growth of the juvenile fish (Menidia menidia) in the natural habitat compared with juveniles reared in the laboratory. Rapp. p.-v. Reun. - Cons. Int. Explor. Mer 178:324-326. 
Bengtson, D. A.

1982. Resource partitioning by Menidia menidia (Linnaeus) and Menidia beryllina (Cope) in two Rhode Island estuaries. Ph.D. diss., 214 p. Univ. Rhode Island, Kingston, RI.

1985. Laboratory experiments on mechanisms of competition and resource partitioning between Menidia menidia (L.) and Menidia beryllina (Cope) (Osteichthyes: Atherinidae). J. Exp. Mar. Biol. Ecol. 92:1-18. Article

Conover, D. O.

1985. Field and laboratory assessment of patterns in fecundity of a multiple spawning fish: the Atlantic silverside Menidia menidia. Fish. Bull. 83:331-341.

Conover, D. O., and B. E. Kynard.

1981. Environmental sex determination: interaction of temperature and genotype in a fish. Science 213:577-579. Article

1984. Field and laboratory observations of spawning periodicity and behavior of a northern population of the Atlantic silverside, Menidia menidia (Pisces: Atherinidae). Environ. Biol. Fish. 11:161-171. Article

Conover, D. O., and S. B. Munch.

2002. Sustaining fisheries yields over evolutionary time scales. Science 297:94-96. Article

Deacutis, C. F.

1978. Effect of thermal shock on predator avoidance by larvae of two fish species. Trans. Am. Fish. Soc. 107:632-635. Article

Fay, C. W., R. J. Neves, and G. B. Pardue.

1983. Species profiles: life histories and environmental requirements of coastal fishes and invertebrates (Mid-Atlantic)_Atlantic silverside. U.S. Fish Wildl. Serv., Div. Biol. Serv., FWS/OBS-82/11.10. U.S. Army Corps Eng., TR EL-82-4, 15 p. [Available at website.]

Gaines, A. G.

1975. Papers on the geomorphology, hydrography and geochemistry of the Pettaquamscutt River estuary. Ph.D. diss., 278 p. Univ. Rhode Island, Kingston, RI. [Available at website.]

Hewitt, R.

1981. The value of pattern in the distribution of young fish. Rapp. p.-v. Reun. Cons. Int. Explor. Mer 178:229-236.

Huber, M.

1995. Environmental control of reproduction in an estuarine fish, Menidia beryllina (Cope) in Rhode Island. Ph.D. diss., 167 p. Univ. Rhode Island, Kingston, RI.

Huber, M., and D. A. Bengtson.

1999. Interspecific differences in growth of somatic and reproductive tissues during the breeding season in Menidia menidia and M. beryllina. J. Fish Biol. 55:274-287. Article

Hyslop, E. J.

1980. Stomach contents analysis - a review of methods and their application. J. Fish Biol. 17:411-429. Article

Jackman, S.

2015. pscl: classes and methods for $\mathrm{R}$ developed in the Po- litical Science Computational Laboratory, Dep. Political Sci., Stanford Univ., Stanford, CA. Manual for R package vers. 1.4.9. [Available at website.]

Lankford, T. E., Jr., J. M. Billerbeck, and D. O. Conover.

2001. Evolution of intrinsic growth and energy acquisition rates. II. Trade-offs with vulnerability to predation in Menidia menidia. Evolution 55:1873-1881. Article

Lindsay, J. A., E. R. Radle, and J. C. S. Wang.

1978. A supplemental sampling method for estuarine ichthyoplankton with emphasis on the Atherinidae. Estuaries 1:61-64.

Middaugh, D. P.

1981. Reproductive ecology and spawning periodicity of the Atlantic silverside, Menidia menidia (Pisces: Atherinidae). Copeia 1981:766-776. Article

Middaugh, D. P., and P. W. Lempesis.

1976. Laboratory spawning and rearing of a marine fish, the silverside Menidia menidia menidia. Mar. Biol. 35:295300. Article

Middaugh, D. P., G. I. Scott, and J. M. Dean.

1981. Reproductive behavior of the Atlantic silverside, Menidia menidia (Pisces, Atherinidae). Environ. Biol. Fish. 6:269-276. Article

Morgan, R. P., II, and R. D. Prince.

1977. Chlorine toxicity to eggs and larvae of five Chesapeake Bay fishes. Trans. Am. Fish. Soc. 106:380-385. Article

Mulkana, M. S.

1966. The growth and feeding habits of juvenile fishes in two Rhode Island estuaries. Gulf Res. Rep. 2:97-167. Article

$\mathrm{R}$ Core Team.

2015. R: a language and environment for statistical computing. R Foundation for Statistical Computing, Vienna, Austria. [Available at website, accessed December 2015.]

Shaw, E.

1960. The development of schooling behavior in fishes. Physiol. Zool. 33:79-86. Article

1961. The development of schooling behavior in fishes. II. Physiol. Zool. 34:263-272. Article

Tewksbury, H. T., II, and D. O. Conover.

1987. Adaptive significance of intertidal egg deposition in the Atlantic silverside Menidia Menidia . Copeia 1987:7683. Article

Volson, B.

2012. Effects of zooplankton community structure and nutritional value on the eggs and larvae of two estuarine fish species. Ph.D. diss., 288 p. Univ. Rhode Island, Kingston, RI. [Available at website.]

White, G. C., and R E. Bennetts.

1996. Analysis of frequency count data using the negative binomial distribution. Ecology 77:2549-2557. Article

Zeileis, A., C. Kleiber, and S. Jackman.

2008. Regression models for count data in R. J. Stat. Software 27(8):1-25. Article 